\title{
Acoustic and optical methods to infer water transparency at Time Series Station Spiekeroog, Wadden Sea
}

\author{
Anne-Christin Schulz ${ }^{1}$, Thomas H. Badewien ${ }^{1}$, Shungudzemwoyo P. Garaba ${ }^{2}$, and Oliver Zielinski ${ }^{1}$ \\ ${ }^{1}$ Institute for Chemistry and Biology of the Marine Environment, Carl von Ossietzky University of Oldenburg, \\ Schleusenstr. 1, 26382 Wilhelmshaven, Germany \\ ${ }^{2}$ Department of Marine Sciences, Avery Point Campus, University of Connecticut, 1080 Shennecosset Road, \\ Groton, CT 06340, USA
}

Correspondence to: Oliver Zielinski (oliver.zielinski@uni-oldenburg.de)

Received: 30 April 2016 - Published in Ocean Sci. Discuss.: 30 May 2016

Revised: 22 September 2016 - Accepted: 12 October 2016 - Published: 4 November 2016

\begin{abstract}
Water transparency is a primary indicator of optical water quality that is driven by suspended particulate and dissolved material. A data set from the operational Time Series Station Spiekeroog located at a tidal inlet of the Wadden Sea was used to perform (i) an inter-comparison of observations related to water transparency, (ii) correlation tests among these measured parameters, and (iii) to explore the utility of both acoustic and optical tools in monitoring water transparency. An Acoustic Doppler Current Profiler was used to derive the backscatter signal in the water column. Optical observations were collected using above-water hyperspectral radiometers and a submerged turbidity metre. Bio-fouling on the turbidity sensors optical windows resulted in measurement drift and abnormal values during quality control steps. We observed significant correlations between turbidity collected by the submerged metre and that derived from abovewater radiometer observations. Turbidity from these sensors was also associated with the backscatter signal derived from the acoustic measurements. These findings suggest that both optical and acoustic measurements can be reasonable proxies of water transparency with the potential to mitigate gaps and increase data quality in long-time observation of marine environments.
\end{abstract}

\section{Introduction}

Over the past decades, scientists, policy makers, and the public have become more aware of issues of environmental concern such as water quality (WFD, 2000; OECD, 1993; Borja et al., 2013). To better understand the dynamics of water quality, it is necessary to use different platforms and tools, which allow for collecting data over a broad range of temporal and spatial scales (Zielinski et al., 2009; Pearlman et al., 2014). The information from these different tools ought to be comparable for a comprehensive and reliable view of these dynamics. Water quality in general is the state of a water body parameterized according to predefined thresholds typically grouped according to ecological, chemical, optical, or morphological properties. Water transparency is determined from optical observations that involve using the human eye as a tool or methods that replicate the human eye sensing approach (Moore et al., 2009). Optical water quality has been determined for decades as the tools needed are easy to use, fast, inexpensive, and robust. Common optical observations provide information about the light availability in the water column, which can be translated into water transparency. Turbidity is one such measurement referring to a relative index of water cloudiness influenced by the inherent dissolved and particulate material (Kirk, 1985; Moore, 1980). Another parameter derived from ocean colour remote sensing is remote sensing reflectance $\left(R_{\mathrm{RS}}\right)$ also known as an essential climate variable. $R_{\mathrm{RS}}$ is a proxy for the apparent colour of water driven by optically active constituents of water (Garaba et al., 2015; Garaba and Zielinski, 2013; GCOS, 2011; Morel, 1980). The natural colour of water, driven by the optically active constituents of water and environmental conditions, can be distinguished using a standard Forel-Ule comparator scale. The Forel-Ule colour scale assigns numbers to the colour of a natural water body, ranging from 1 
(indigo-blue) to 21 (cola brown). This information can also be derived from $R_{\mathrm{RS}}$ information (Garaba et al., 2014; Wernand and van der Woerd, 2010).

Over the past decades, measurement methods based on acoustic backscatter have been increasingly used to estimate the abundance and distributional patterns of suspended matter (Deines, 1999; Thorne et al., 1991). Indeed, acoustics is one of those technologies advancing our capabilities to probe sediment processes (Thorne and Hanes, 2002; Voulgaris and Meyers, 2004). The acoustic backscatter signal is used to quantitatively determine suspended matter and therefore relates to turbidity (Deines, 1999; Lohrmann, 2001; Schulz et al., 2015). Therefore, acoustic backscatter signals provide information about the suspended material in a given water body and enable one to record the changes over a long timescale. An Acoustic Doppler Current Profiler (ADCP), for example, measures non-intrusively and threedimensionally, making it a very powerful tool for examining small-scale sediment transport processes (Thorne and Hanes, 2002; Schulz et al., 2015).

The composition and concentration of suspended material is highly variable in coastal and estuarine regions (Winter et al., 2007; Fugate and Friedrichs, 2002). Fragile flocculants change their characteristics over short and over long timescales due to hydrodynamic forcing such as currents, turbulence and tides (Vousdoukas et al., 2011; Burchard and Badewien, 2015). Optical (White, 1998; Sutherland et al., 2000) and acoustic methods (Voulgaris and Meyers, 2004; Fugate and Friedrichs, 2002) typically reveal different scattering properties of the sediment. Thus, Winter et al. (2007) concluded that the combination of different instruments reveal different aspects of suspended particulate matter (SPM) dynamics.

The aim of this work is to find out whether measurements of acoustic backscatter can be reliably related to optical water properties. As all these observations provide information about the inherent suspended particulate and dissolved material, these should also be suited as practical indicators of water transparency and thus quality. We also evaluate the utility of acoustic and optical technology in environmental monitoring to gather qualitative and quantitative indicators of change within natural waters taking advantage of operational long time series observatory platforms. The goals of this study will be towards (i) inter-comparison of measurements from different tools, (ii) understanding correlations among the observed variables, and (ii) developing methods geared to closing gaps in relevant information about variability in water transparency in the water column such as when individual instruments fail.

\section{Materials and methods}

\subsection{Study area}

Time Series Station Spiekeroog (TSS; Fig. 1) is a multidisciplinary, autonomously operating observatory located in a tidal channel between the islands of Langeoog and Spiekeroog at $53^{\circ} 45.016^{\prime} \mathrm{N}, 7^{\circ} 40.266^{\prime} \mathrm{E}$ (Reuter et al., 2009). These islands are part of an island barrier system in the East Frisian Wadden Sea, southern North Sea, which belongs to the UNESCO World Natural Heritage sites. The region is part of an extended North Sea tidal flat system with shallow water depths ranging from 0 to $20 \mathrm{~m}$, with current velocities of up to $2 \mathrm{~m} \mathrm{~s}^{-1}$. The tidal cycle is semi-diurnal. The water depth at the TSS Spiekeroog is about $13.5 \mathrm{~m}$, with a tidal range of about $2.7 \mathrm{~m}$ (Holinde et al., 2015). Here, the distribution of suspended particulate inorganic and organic material is strongly influenced by tidal currents as well as by wind-driven waves (Bartholomä et al., 2009; Badewien et al., 2009). Because of these strong and rapid dynamics, the area at the TSS is well suited for studying the biogeochemical and physical processes occurring at the transition from the coast to the open sea.

\subsection{Sampling and analysis}

Hyperspectral radiometers were used to collect and derive $R_{\mathrm{RS}}$ data at $24 \mathrm{~m}$ above the seafloor at $5 \mathrm{~min}$ interval continuously. The reflectance measurements, corrected for environmental perturbations, were transformed into Forel-Ule colour indices that can be matched to the intrinsic colour of water. A submerged WETlabs ECO FLNTU sensor measured turbidity at $12 \mathrm{~m}$ above the seafloor continuously at 1 min intervals. The ECO FLNTU sensor samples turbidity data with optical backscattering at a wavelength of $700 \mathrm{~nm}$. Detailed information on the processing of these measurements is presented in an earlier study from Garaba et al. (2014).

A bottom-mounted (1.5 $\mathrm{m}$ above the seafloor), upward looking $1200 \mathrm{kHz}$ ADCP (Teledyne RD Instruments Workhorse Sentinel, USA) was used to estimate the current velocity using the Doppler effect in three dimensions. The ADCP is installed at a distance of $12 \mathrm{~m}$ north-north-west of the station's pole. We receive data over the entire water depth with a vertical resolution of $0.20 \mathrm{~m}$ (bin size) and a temporal resolution of $5 \mathrm{~min}$ (measurements are averaged over 45 pings in $5 \mathrm{~min}$ bursts). The shape of the depth profiles derived from the backscatter data (Fig. 2) vary depending on the tidal phase (flood, ebb, slack water). Those phases with similar current velocity also result in similar shapes of the backscatter profiles. Because the ADCP has a beam angle of $20^{\circ}$ and a tilted orientation with a pitch of $\sim 19.39^{\circ}$ and a roll of $\sim 17.96^{\circ}$, the maximum range $R_{\max }$ in metres of acceptable data is given by

$R_{\max }=D \cos (\phi)$ 


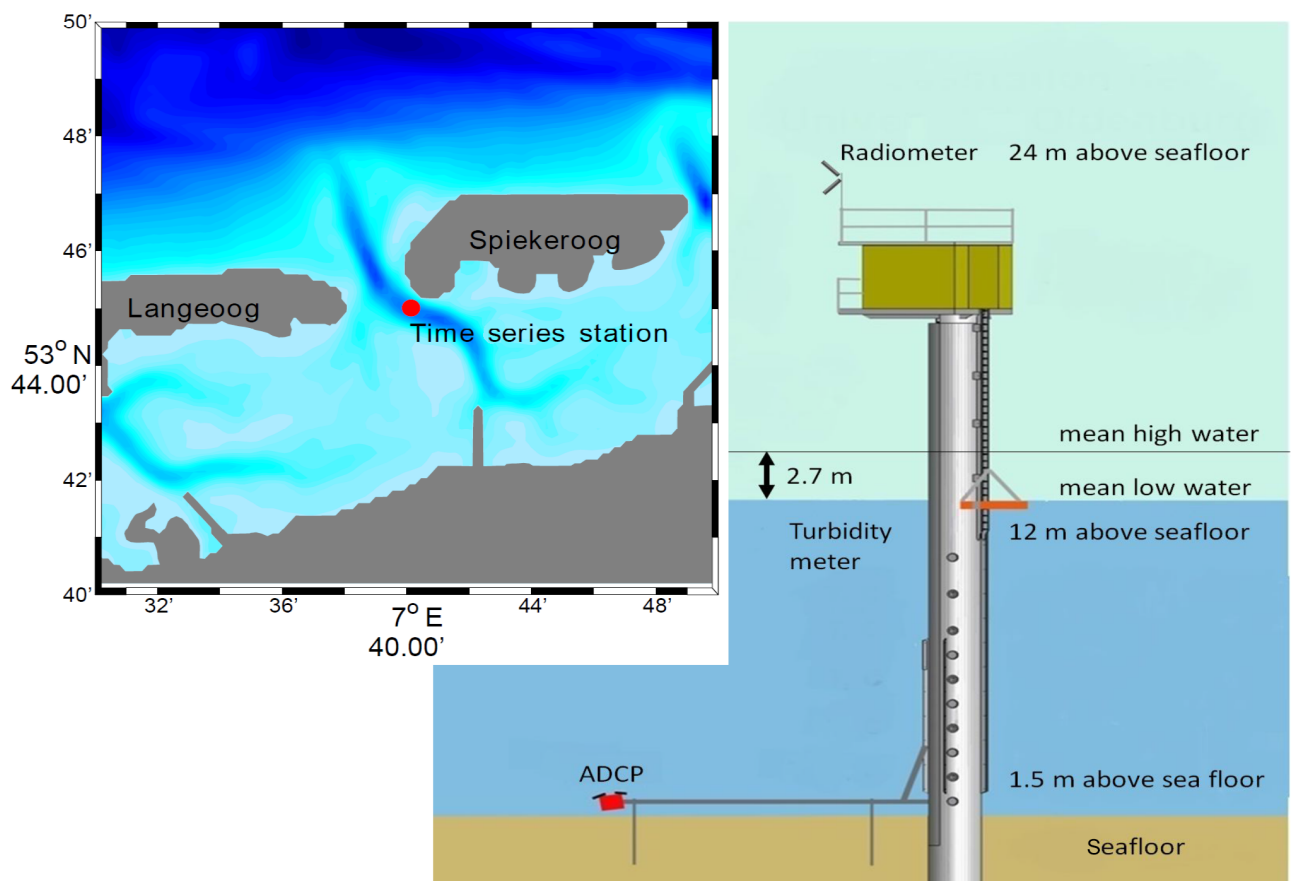

Figure 1. Schematic of the Time Series Station Spiekeroog showing the position of the radiometers ( $24 \mathrm{~m})$, the turbidity metre (12 $\mathrm{m})$, and the ADCP ( $1.5 \mathrm{~m}$ above the seafloor). The typical water depth is $13.5 \mathrm{~m}$ with tidal range of about $2.7 \mathrm{~m}$ between mean high and low water. The insert shows the location of the Time Series Station where the colours indicate the water depth at high water.

where $D$ is the distance between the ADCP and the surface in metres, and $\phi$ is the angle in degrees of the beam relative to the vertical. The resulting blank space near the surface reached values between 3.0 and $3.5 \mathrm{~m}$ (see Fig. 3). To compare the data at nearly the same sampling target, we extrapolate the acoustic backscatter signal to the sea surface area (details of the sampling areas of the different sensors are shown in Fig. 4), using the acceptable acoustic backscatter data until $R_{\max }$ depth. To do so, we applied various curve fitting techniques using MATLAB R2015a Curve Fitting Toolbox (MathWorks, USA). These methods were (i) the exponential fitting method (exp, equation: $a \cdot \exp (b \cdot x)$ ), (ii) the polynomial fitting method (poly, equation: $p 1 \cdot x+p 2$, basically linear), (iii) the power fitting method (power, equation: $a \cdot x^{b}$ ), and (iv) constant extrapolation (using the last reliable data value as the surface value). Applications of these methods are shown in Fig. 5. The top panels show profiles, which are exemplary for data obtained during low water and one during flooding (violet and blue in Fig. 2) with different extrapolations to the surface layer. These panels also demonstrate the different ranges that were used for extrapolating; data were extrapolated using measurements obtained within the entire water column (left panel). In an alternative approach, extrapolation of data was based solely on measurements not affected by bottom friction - that is data derived in the near-bottom range up to $4 \mathrm{~m}$ were excluded (right panel). In this range, the impact of ebb- and flood-induced currents is strong. The bottom panel shows the summary of all $R^{2} \mathrm{ob}-$ tained from the different extrapolation methods on the entire data set. We assume that the distribution of suspended matter near the surface layer is nearly homogeneous (e.g. Badewien et al., 2009; van der Hout et al., 2015) because of turbulence and wind influence.

The exponential extrapolation (exp) resulted in the best fits for all data sets and extrapolation ranges. The $R^{2}$ values over the entire period are good with $R^{2}>0.99$ (see Fig. 5, bottom). Therefore, to compare acoustic backscatter data with the other parameters, the exponential fitting method and the extrapolations with constant values $\left(\mathrm{BS}_{\mathrm{Ex}, \exp }\right.$ and $\left.\mathrm{BS}_{\mathrm{Ex}, \text { const }}\right)$ were used. The latter was based on the assumption of homogeneity in the top layer of the water column.

\section{Results}

The turbidity time series (Fig. 6 displayed data obtained from 29 August 2013 to 2 September 2013) shows a rapid response directly after cleaning the ECO FLNTU sensor as expected in a highly bio-active season (summer). Even in this short time period of 5 days a strong increase and spreading of turbidity values are apparent. On 28 August 2013, the ECO FLNTU sensor was cleaned. Directly after cleaning, the values were below 5 NTU (nephelometric turbidity units) with a range of $2.2 \mathrm{NTU}$. After 3 days, the values increased and reached maximum values of up to $25 \mathrm{NTU}$ with spreading out to $10 \mathrm{NTU}$ at the end of the 5-day period. These values 


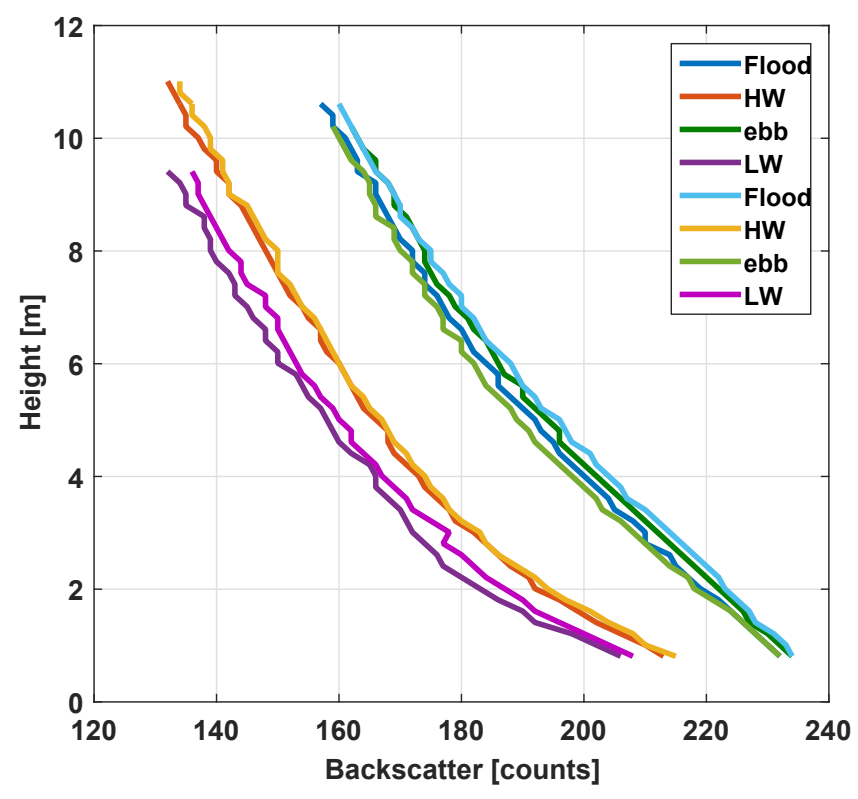

Figure 2. Example acoustic backscatter profiles measured from ADCP over height in counts observed on 29 August 2013 at different tidal phases: flood, ebb, slack water (high water (HW), low water (LW)).

indicate that the upper limit of reliable measurements had been reached. Figure 7 presents a closer look at the variables of the acoustic and optical measurements obtained on $29 \mathrm{Au}-$ gust 2013. Visual inspection of data (Forel-Ule index, turbidity and the acoustic backscatter) suggested that there was a moderate correlation. As expected, the highest values of the variables investigated were during periods with high current speeds, i.e. when the water level rises or falls. Because of the measurement principle the Forel-Ule index was restricted to a time span between 06:00 and 18:00 resulting from daytime and the reflectance of the sunlight. The signals of both the Forel-Ule index FUI and the turbidity TRB were stronger during ebb tide than during flood tide. The acoustic backscatter signals, which were extrapolated using constant values $\mathrm{BS}_{\mathrm{Ex}, \mathrm{const}}$, were nearly equal strength during ebb and flood tide, whereas $\mathrm{BS}_{\mathrm{Ex}, \text { exp }}$ exhibited stronger ebb signal. However, during slack water the values were slightly decreasing. Thus, the dynamics of all data sets corresponded well to the observed tidal signal.

Results of the Spearman rank correlation for 1 day (29 August 2013, directly after sensor cleaning) and for a longer period (5 days) are shown in Table 1. As described above, we extrapolated the acoustic backscatter signal towards the sea surface to be able to compare these acoustic measurements with the optical approaches. Two of these extrapolated variables (BS $\mathrm{Bx}_{\mathrm{Ex}, \mathrm{const}}$ and $\mathrm{BS}_{\mathrm{Ex}, \text { exp }}$ ) were used for the Spearman rank correlation test. The correlation coefficient between the data sets increased from moderate $\left(\rho_{\text {Spearman }}>0.4\right.$ and $\left.\rho_{\text {Spearman }}<0.6\right)$ to strong $\left(\rho_{\text {Spearman }}>0.6\right.$ and $\rho_{\text {Spearman }}<$
$0.8)$. In general, the correlation values of the shorter time periods were higher, than the values for the longer time period, especially for the comparison of the acoustic backscatter signal and the turbidity. The correlation between FUI and TRB was also very good $\left(\rho_{\text {Spearman }}>0.8\right)$. The comparison of the two different time periods showed nearly the same values. For further investigations, we used the constant extrapolated acoustic backscatter signal $\mathrm{BS}_{\mathrm{Ex}, \mathrm{const}}$. For this approach, we assumed a homogenous surface layer (see above).

Table 2 shows a comparison between the constantly extrapolated ADCP backscatter signal BS $\mathrm{Ex}_{\mathrm{Ex} \text {,const }}$ and the ForelUle index and the turbidity data separated into different tidal phases: ebb, flood, high waters, low waters. The data cover the time period from 29 August 2013 to 2 September 2013. The correlations between the acoustic backscatter data $\mathrm{BS}_{\mathrm{Ex} \text {,const }}$ and FUI ranged from a weak correlation of $\rho_{\text {Spearman }}=0.34$ during high tide to a strong correlation during low tide of $\rho_{\text {Spearman }}=0.81$. In between, the methods correlated mostly moderate $\left(\rho_{\text {Spearman }}>0.4\right.$ and $\rho_{\text {Spearman }}<$ 0.6). The correlations between acoustic backscatter data $\mathrm{BS}_{\mathrm{Ex}, \mathrm{const}}$ and TRB were weak at high tide and flood, and otherwise strong $\left(\rho_{\text {Spearman }}>0.6\right.$ and $\left.\rho_{\text {Spearman }}<0.8\right)$.

\section{Discussion}

The time series of turbidity data shown in Fig. 6 indicate the strong influence of bio-fouling on the sensors during the bioactive seasons spring and summer even during shorter time periods of several days. Thus, it is vital to regularly check and, if necessary, clean sensors to reduce the impact of biofouling on data quality. The merely moderate correlation between the acoustic backscatter data $\mathrm{BS}_{\mathrm{Ex}, \mathrm{const}}$ and the ForelUle index and turbidity (seen in Fig. 7 and Table 1) presumably results from the fact that the sensors had different positions, namely, above the sea surface, submerged near the sea surface and submerged near the seafloor (an overview of the fields of view is shown in Fig. 4). Additionally, the lack of a strong correlation may be due to different scattering characteristics of suspended sediment (White, 1998; Sutherland et al., 2000; Voulgaris and Meyers, 2004; Fugate and Friedrichs, 2002) depending on whether optical or acoustic methods are applied. Comparisons of acoustic and optical sensors for measurements of suspended sediment concentrations performed under laboratory conditions showed that most in-water sensors have a linear response under bimodal and randomly sorted suspended sediments (Vousdoukas et al., 2011). Optical measurements are more sensitive to fine sediment and are wavelength dependent, while acoustic measurements are more sensitive to coarser material, depending on the operating frequency (Gartner, 2004). Both depend on the amount of suspended sediment in the water column. Badewien et al. (2009) measured a range of particle sizes from 1.25 to $26.9 \mu \mathrm{m}$ (radius) at the same site. Therefore, mainly fine sediment concentrations are expected. A 


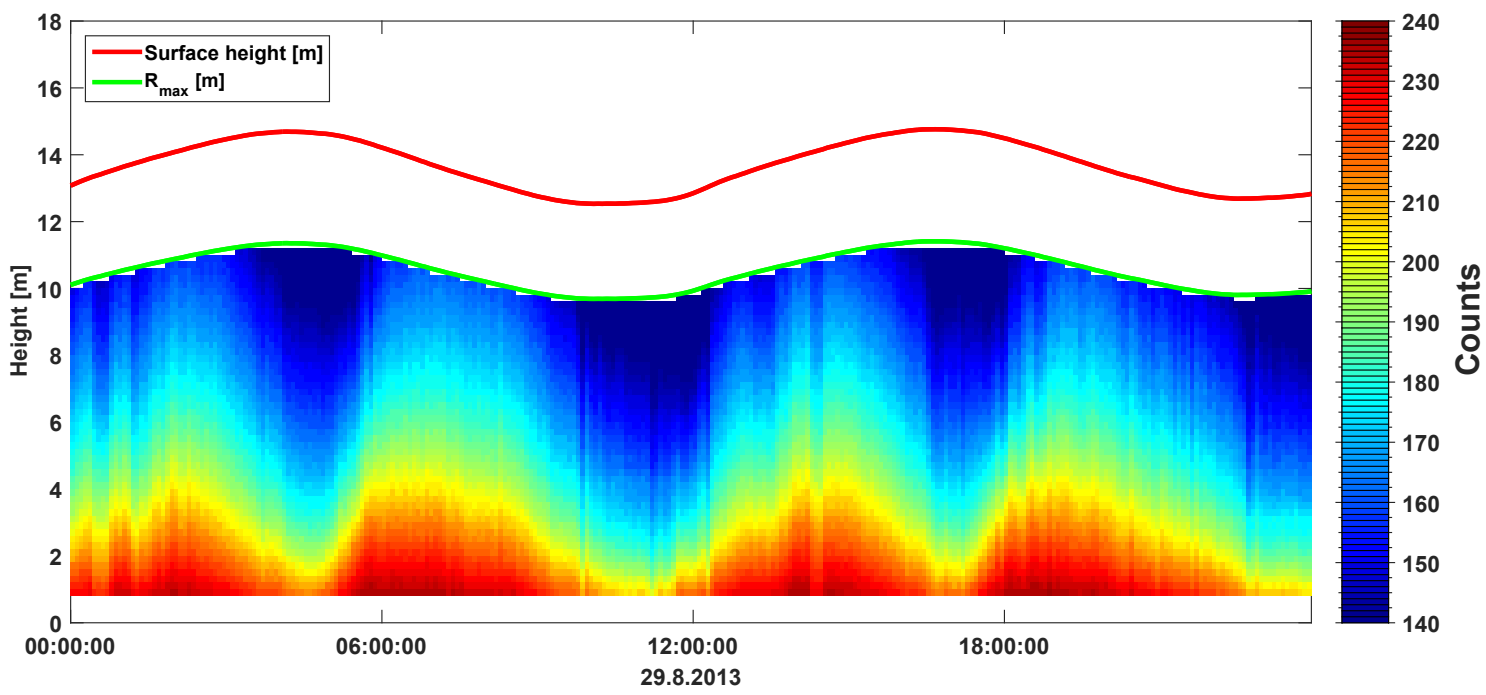

Figure 3. An example of acoustic backscatter signal in counts measured with the ADCP (from the seafloor upwards through the water column), acceptable backscatter data until $R_{\max }$. Green line: $R_{\max }$ depth in metres; red line: sea level (height in metres) observed on 29 August 2013.
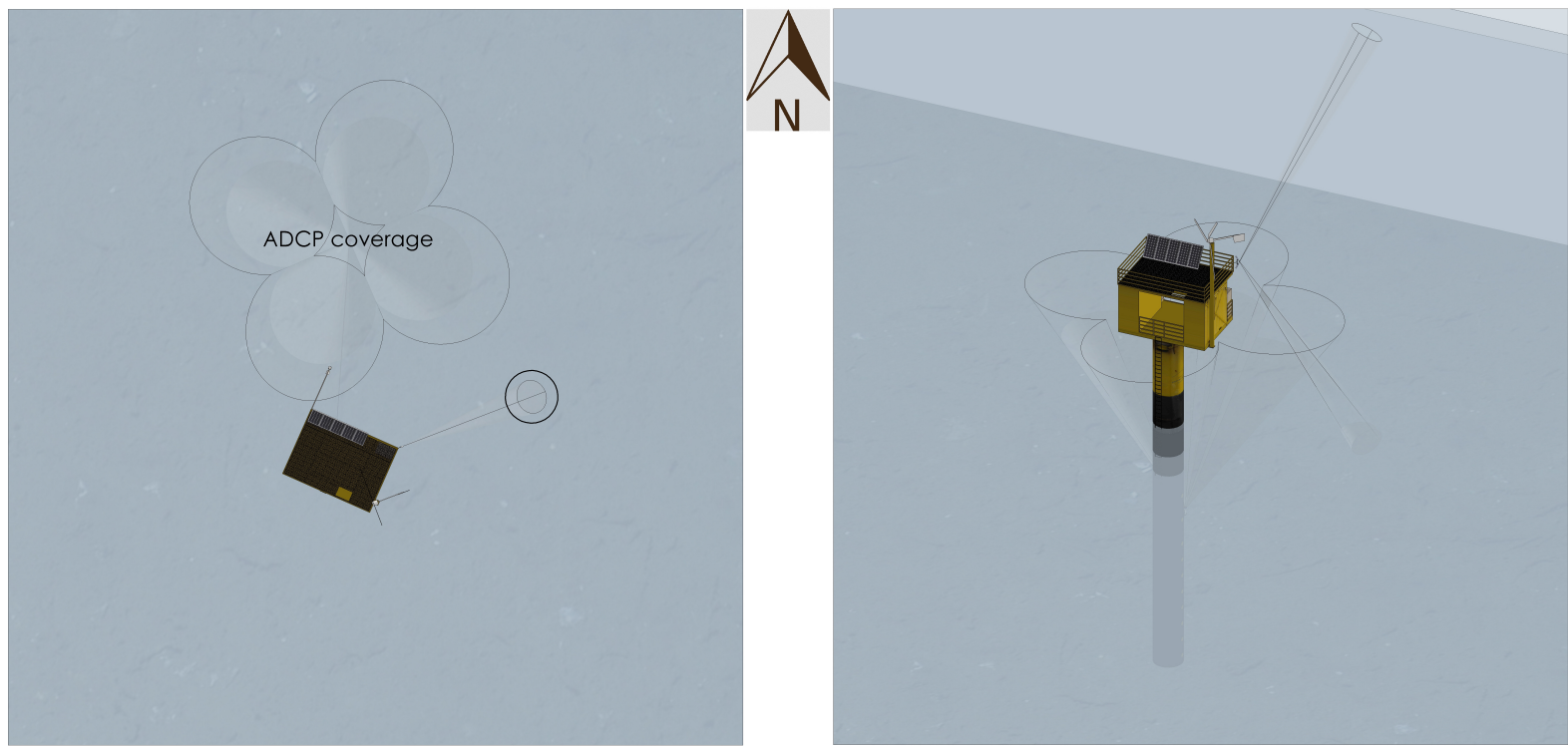

Figure 4. Schematic of the different measurement fields of view (FOV) of the sensors at the Time Series Station Spiekeroog at high water. Left panel: top view; right panel: perspective from south (provided by Nick Rüssmeier).

modelling study by Stanev et al. (2007) showed different sediment concentrations and dynamics for fine SPM (mud, $d_{\text {mud }}=63 \mu \mathrm{m}$; d: diameter $)$ and sand $\left(d_{\text {sand }}=200 \mu \mathrm{m}\right)$ for this Wadden Sea area. Depending on the specific location, the dynamics of the different sediment types (fine or coarse) act differently dependent on the tidal signal. Concentrations of coarser material usually clearly peak at maximum flow velocities (flood and ebb). The concentration of fine sediments is the highest during ebb, although the peak is broader. The peak during flood is less pronounced. In this study, the dynamics observed in all data sets corresponds well to the ob- served tidal signal (Fig. 7). As shown in Schulz et al. (2015) the remaining shear currents in the surface layer kept particles within the water column at slack water times. Thus, we assume that the instruments used in this study provide reasonable proxies for suspended material which is comparable in size.

To be able to compare the data obtained by different methods at about the same sampling site, we had to extrapolate the acoustic backscatter signal towards the sea surface as described above. Two of these extrapolated variables $\left(\mathrm{BS}_{\mathrm{Ex}, \mathrm{const}}\right.$ and $\left.\mathrm{BS}_{\mathrm{Ex}, \exp }\right)$ were used for the Spearman rank 

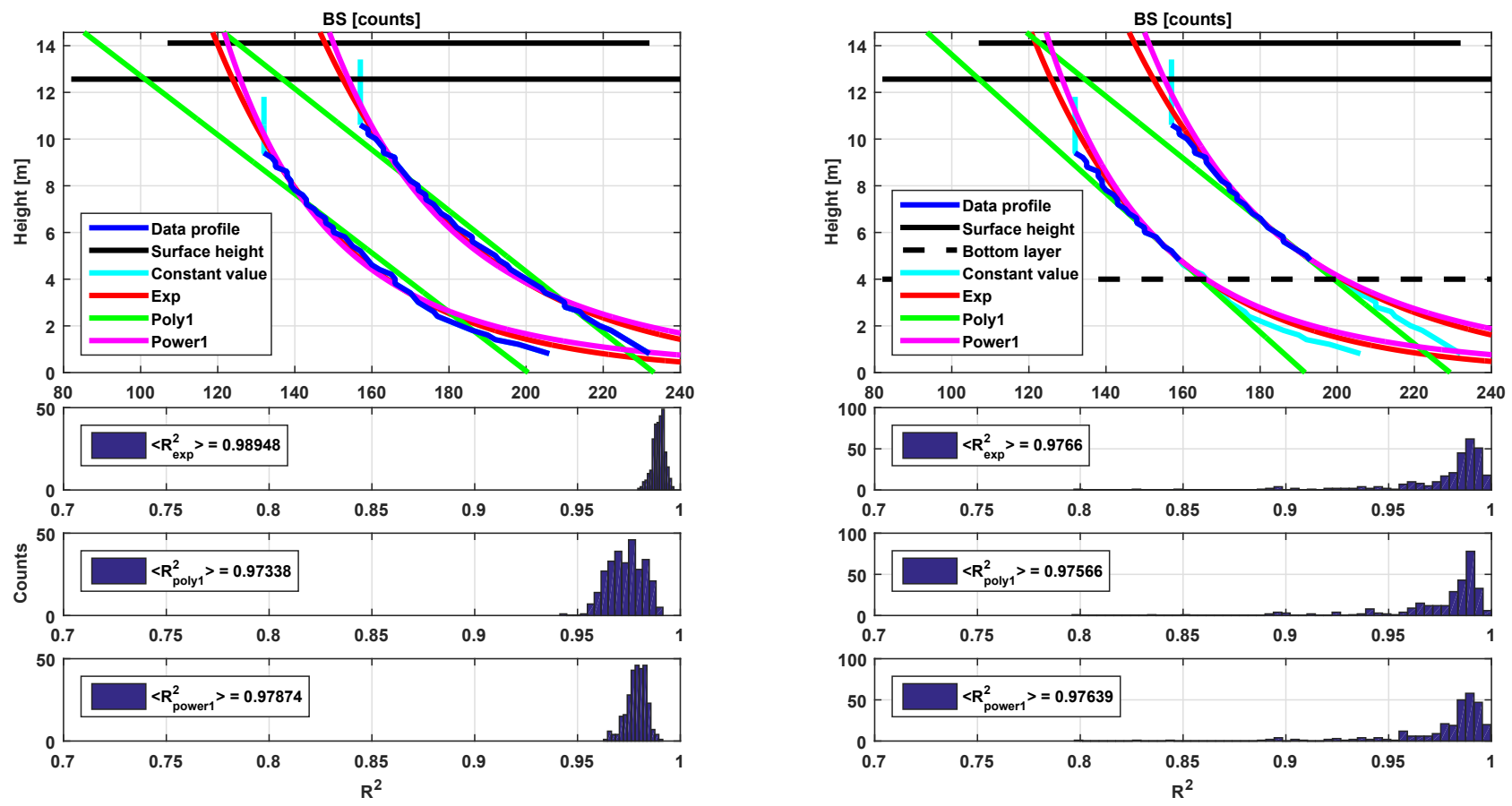

Figure 5. Selected acoustic backscatter profiles during low water and during flooding; top left: extrapolation through the whole water column; top right: extrapolation through the reduced water column. The coloured profiles show the results of the different extrapolation methods (cyan: constant extrapolation; red: exponential extrapolation; green: polynomial extrapolation; magenta: power extrapolation). Black line: surface layer and black dotted line: lower layer. Bottom panels: histograms of the corresponding $R^{2}$ values (from every profile) for the entire period; left: for the whole water column, right: for the reduced water column.

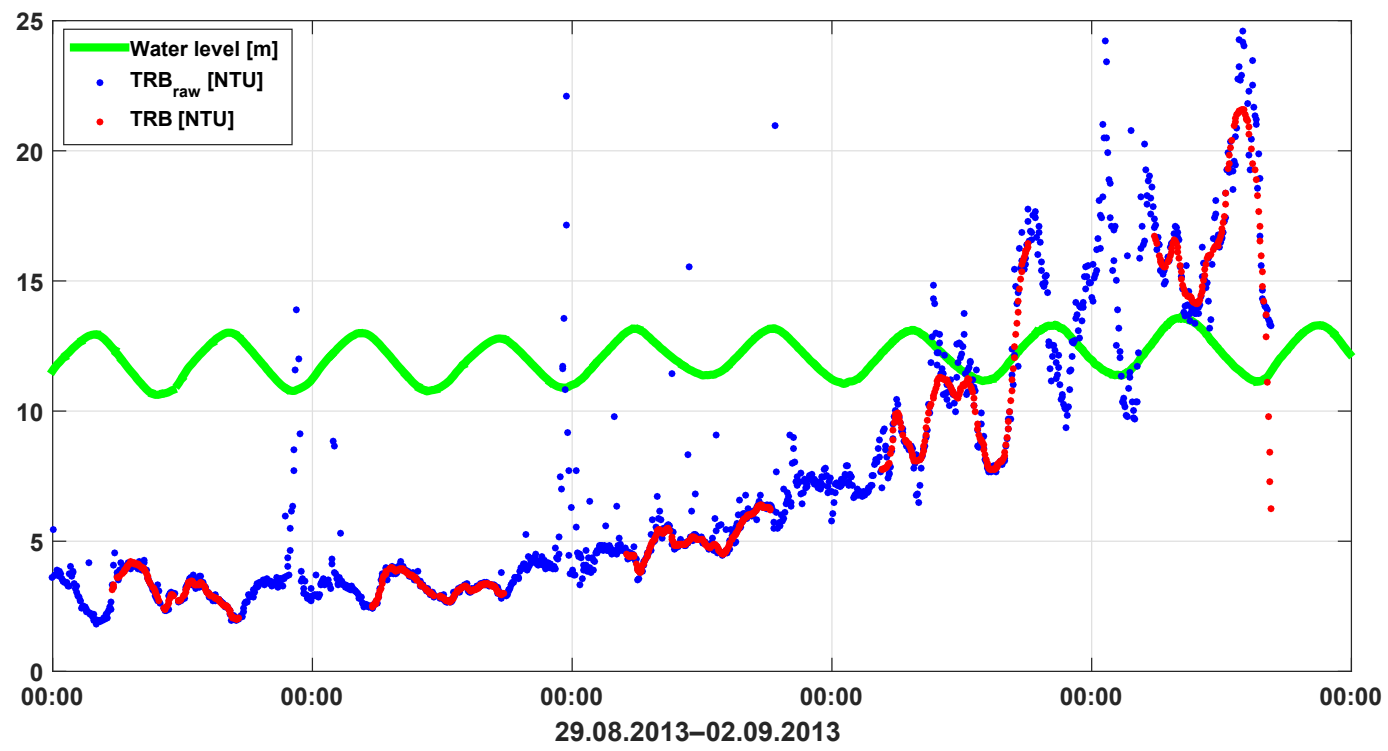

Figure 6. Turbidity data in NTU from 29 August 2013 to 2 September 2013, limited in range (0-25 NTU), blue: raw data, red: quality checked data, and green: water level in metres.

correlation test, as shown in Table 1 and 2. The correlation coefficient between the data sets increased from moderate to strong. These differences may result from the different scat- tering characteristics and dynamics of the kinds of sediment, which occur in this location.

The bio-fouling influence started already in the short 5day time period. Therefore, correlation values derived from 


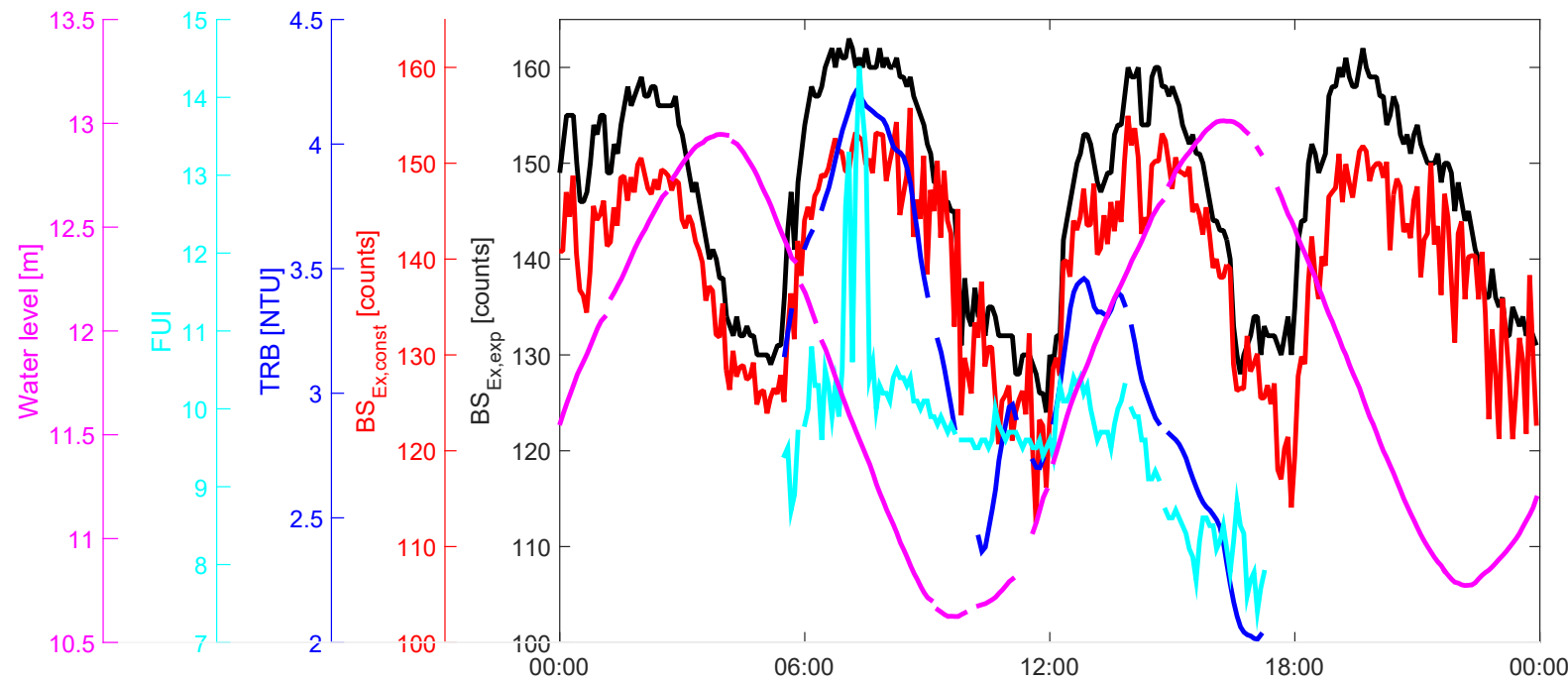

Figure 7. Time series observations on 29 August 2013 of Forel-Ule colour index (FUI; cyan), backscatter signal (BS; constant extrapolation: red, exponential extrapolation: black), turbidity (blue) and water level (magenta).

Table 1. Spearman rank correlation results of the backscatter data from the ADCP BS $\mathrm{EX}_{\text {,const }}$ and BS $\mathrm{EX,exp}$ for 1 day and for a longer time period (29 August 2013-2 September 2013) as well as the estimated Forel-Ule index FUI and the turbidity TRB.

\begin{tabular}{lrrrr}
\hline Variables & $\begin{array}{r}\rho_{\text {Spearman }} \\
1 \text { day }\end{array}$ & $\begin{array}{r}\rho_{\text {Spearman }} \\
\text { longer period }\end{array}$ & $\begin{array}{r}p \text { value } \\
1 \text { day }\end{array}$ & $\begin{array}{r}p \text { value } \\
\text { longer period }\end{array}$ \\
\hline BS $_{\text {EX,const vs. TRB }}$ & 0.78 & 0.50 & $<0.001$ & $<0.001$ \\
BS $_{\text {EX,exp vs. TRB }}$ & 0.67 & 0.42 & $<0.001$ & $<0.001$ \\
BS $_{\text {EX,const vs. FUI }}$ & 0.58 & 0.52 & $<0.001$ & $<0.001$ \\
BS $_{\text {EX,exp vs. FUI }}$ & 0.48 & 0.44 & $<0.001$ & $<0.001$ \\
FUI vs. TRB & 0.88 & 0.85 & $<0.001$ & $<0.001$ \\
\hline
\end{tabular}

Table 2. Spearman rank correlation results of the backscatter data from the ADCP BS $\mathrm{EX}_{\text {,const }}$, the estimated Forel-Ule index FUI, and the turbidity TRB with separation into tidal phases.

\begin{tabular}{llrr}
\hline Variables & Tide phase & $\rho_{\text {Spearman }}$ & $p$ value \\
\hline BS $_{\text {Ex,const vs. FUI }}$ & ebb & 0.45 & $<0.001$ \\
& flood & 0.52 & $<0.00$ \\
& high tide & 0.34 & 0.06 \\
& low tide & 0.81 & $<0.001$ \\
\hline BS $_{\text {Ex,const vs. TRB }}$ & ebb & 0.71 & $<0.001$ \\
& flood & -0.34 & $<0.001$ \\
& high tide & 0.40 & 0.0014 \\
& low tide & 0.77 & $<0.001$ \\
\hline
\end{tabular}

the data of the shorter 1-day time period directly after cleaning the ECO FLNTU sensor were stronger than the values for the entire time period of 5 days. Even the correlation between the FUI and the TRB was very good and the comparison of the two different time periods showed nearly the same values. This indicates that both optical measurements (above and in-water) detect the same type of sediment. In a previous study it was shown that the Forel-Ule index can be used to accurately derive turbidity (Garaba et al., 2014). We therefore evaluated its potential in providing information about suspended material, which in turn can be compared to information derived from acoustic backscatter signals. Our results regarding the correlation between the acoustic backscatter signal and turbidity agree well with the investigations of Schulz et al. (2015). The data sets of the in-water sensors correlated moderately to strongly. In particular, the counter wise strengths of the signals during the tidal cycle could be identified. In summary, our results on the correlation of the different sensor types agree well with previous results from laboratory investigations (Vousdoukas et al., 2011).

\section{Conclusions}

The goals of this study were to perform an inter-comparison of measurements from different tools, to understand correlations among the observed variables, and to develop methods geared to closing gaps in relevant information about variabil- 
ity in water transparency in the water column when individual instruments fail.

The results of this study show that bio-fouling decreases the data quality of in-water optical measurements of turbidity within short time periods. Hence, it is important to find an approach to improve the monitoring over time and increase the robustness of the turbidity results. This study demonstrates that bottom-mounted ADCP measurements, which are hardly influenced by bio-fouling, can be a suitable alternative to overcome the problem. We found that using the acoustic backscatter signal and the Forel-Ule index both yield reliable results, thus broadening the work of Garaba et al. (2014). On a qualitative level, using the Forel-Ule index, as derived from radiometer measurements, is a powerful tool for exchangeable estimations of water transparency as much as data sets derived from ADCP measurements.

We have shown that data sets from different measurement principles (optical and acoustic) are comparable and complementary. This is even though the different sensors reveal different scattering properties of particles and are positioned in different ways, i.e. above the sea surface, submerged near the sea surface, and submerged near the seafloor.

Thus, our study strongly suggests that combining these methods can be an effective tool to monitor environmental processes as a part of long time series observatories.

\section{The Supplement related to this article is available online at doi:10.5194/os-12-1155-2016-supplement.}

Acknowledgements. We would like to thank Axel Braun, Helmo Nicolai, Gerrit Behrens, and Waldemar Siewert for their ongoing technical assistance and support in all our experimental work and the maintenance of the Time Series Station Spiekeroog. We also thank Constanze Böttcher for English language editing. Thanks to Nick Rüssmeier for CAD illustration. This work has been supported through the Coastal Observing System for Northern and Arctic Seas (COSYNA) funded by the German Federal Ministry of Education and Research through the Helmholtz Association and coordinated by the Helmholtz-Zentrum Geesthacht. We are grateful to the comments from the two anonymous reviewers.

Edited by: R. Dewey

Reviewed by: two anonymous referees

\section{References}

Badewien, T. H., Zimmer, E., Bartholomä, A., and Reuter, R.: Towards continuous long-term measurements of suspended particulate matter (SPM) in turbid coastal waters, Ocean Dynam., 59, 227-238, 2009.

Bartholomä, A., Kubicki, A., Badewien, T. H., and Flemming, B. W.: Suspended sediment transport in the German Wadden Sea- seasonal variations and extreme events, Ocean Dynam., 59, 213225, 2009.

Borja, A., Elliott, M., Andersen, J. H., Cardoso, A. C., Carstensen, J., ao G. Ferreira, J., Heiskanen, A.-S., ao C. Marques, J., ao M. Neto, J., Teixeira, H., Uusitalo, L., Uyarra, M. C., and Zampoukas, N.: Good Environmental Status of marine ecosystems: What is it and how do we know when we have attained it?, Mar. Pollut. Bull., 76, 16-27, 2013.

Burchard, H. and Badewien, T. H.: Thermohaline residual circulation of the Wadden Sea, Ocean Dynam., 65, 1-14, doi:10.1007/s10236-015-0895-x, 2015.

Deines, K. L.: Backscatter Estimation Using Broadband Acoustic Doppler Current Profilers, in: Current Measurement, 1999, Proceedings of the IEEE Sixth Working Conference on, 249-253, doi:10.1109/CCM.1999.755249, 1999.

Fugate, D. C. and Friedrichs, C. T.: Determining concentration and fall velocity of estuarine particle populations using ADV, OBS and LISST, Cont. Shelf Res., 22, 1867-1886, 2002.

Garaba, S. P. and Zielinski, O.: Comparison of remote sensing reflectance from above-water and in-water measurements west of Greenland, Labrador Sea, Denmark Strait, and west of Iceland, Opt. Express, 21, 15938-15950, doi:10.1364/OE.21.015938, 2013.

Garaba, S. P., Badewien, T. H., Braun, A., Schulz, A.-C., and Zielinski, O.: Using ocean colour products to estimate turbidity at the Wadden Sea time series station Spiekeroog, J. Eur. Opt. Soc.Rapid, 9, 1-6, doi:10.2971/jeos.2014.14020, 2014.

Garaba, S. P., Voß, D., Wollschläger, J., and Zielinski, O.: Modern approaches to shipborne ocean color remote sensing, Appl. Opt., 54, 3602-3612, 2015.

Gartner, J. W.: Estimating suspended solids concentrations from backscatter intensity measured by acoustic Doppler current profiler in San Francisco Bay, California, Mar. Geol., 211, 169-187, 2004.

GCOS: The Global Climate Observing System - Systematic Observation Requirements for Satellite-based Data Products for Climate: 2011 Update GCOS-154, 2011.

Holinde, L., Badewien, T. H., Freund, J. A., Stanev, E. V., and Zielinski, O.: Processing of water level derived from water pressure data at the Time Series Station Spiekeroog, Earth Syst. Sci. Data, 7, 289-297, doi:10.5194/essd-7-289-2015, 2015.

Kirk, J. T. O.: Effects of suspensoids (turbidity) on penetration of solar radiation in aquatic ecosystems, Hydrobiologia, 125, 195208, 1985.

Lohrmann, A.: Monitoring Sediment Concentration with acoustic backscattering instruments, nortek technical notes/October15, 2001/Document No. N4000-712, 2001.

Moore, C., Barnard, A., Fietzek, P., Lewis, M. R., Sosik, H. M., White, S., and Zielinski, O.: Optical tools for ocean monitoring and research, Ocean Sci., 5, 661-684, doi:10.5194/os-5-6612009, 2009.

Moore, G. K.: Satellite remote sensing of water turbidity / Sonde de télémesure par satellite de la turbidité de l'eau, J. Eur. Opt. Soc.-Rapid, 5, 407-421, 1980.

Morel, A.: In-water and remote measurements of ocean color, Bound.-Layer Meteorol., 18, 177-201, doi:10.1007/bf00121323, 1980.

OECD: Core Set Of Indicators For Environmental Performance Reviews - A synthesis report by the Group on the State of the En- 
vironment, Organisation for Economic Co-operation and Development, Paris, 1993.

Pearlman, J., Garello, R., Delory, E., Castro, A., del Río, J., Toma, D. M., Rolin, J. F., Waldmann, C., and Zielinski, O.: Requirements and approaches for a more costefficient assessment of ocean waters and ecosystems, and fisheries management, in: 2014 Oceans - St. John's, 1-9, doi:10.1109/OCEANS.2014.7003144, 2014

Reuter, R., Badewien, T. H., Bartholomä, A., Braun, A., Lübben, A., and Rullkötter, J.: A hydrographic time series station in the Wadden Sea (southern North Sea), Ocean Dynam., 59, 195, doi:10.1007/s10236-009-0196-3, 2009.

Schulz, A.-C., Badewien, T. H., and Zielinski, O.: Impact of currents and turbulence on turbidity dynamics at the Time Series Station Spiekeroog (Wadden Sea, southern North Sea), IEEE, Current, Waves and Turbulence Measurement (CWTM), 2015 IEEE/OES Eleventh, doi:10.1109/CWTM.2015.7098095, 2015.

Stanev, E. V., Brink-Spalink, G., and Wolff, J.-O.: Sediment dynamics in tidally dominated environments controlled by transport and turbulence: A case study for the East Frisian Wadden Sea, J. Geophys. Res., 112, 1-20, doi:10.1029/2005JC003045, 2007.

Sutherland, T., Lane, P., Amos, C., and Downing, J.: The calibration of optical backscatter sensors for suspended sediment of varying darkness levels, Mar. Geol., 162, 587-597, 2000.

Thorne, P. D. and Hanes, D. M.: A review of acoustic measurement of small-scale sediment processes, Cont. Shelf Res., 22, 603632, 2002.

Thorne, P. D., Vincent, C. E., Hardcastle, P. J., Rehmann, S., and Pearson, N.: Measuring suspended sediment concentrations using acoustic backscatter devices, Mar. Geol., 98, 7-16, 1991. van der Hout, C. M., Gerkema, T., Nauw, J. J., and Ridderinkhof, H.: Observations of a narrow zone of high suspended particulate matter (SPM) concentrations along the Dutch coast, Cont. Shelf Res., 95, 27-38, 2015.

Voulgaris, G. and Meyers, S. T.: Temporal variability of hydrodynamics, sediment concentration and sediment settling velocity in a tidal creek, Cont. Shelf Res., 24, 1659-1683, 2004.

Vousdoukas, M., Aleksiadis, S., Grenz, C., and Verney, R.: Comparisons of acoustic and optical sensors for suspended sediment concentration measurements under non-homogeneous solutions, J. Coast. Res., 64, 160-164, 2011.

Wernand, M. R. and van der Woerd, H. J.: Spectral analysis of the Forel-Ule Ocean colour comparator scale, J. Eur. Opt. Soc.Rapid, 5, 10014s, doi:10.2971/jeos.2010.10014s, 2010.

WFD: European Water Framework Directive, Directive 2000/60/EC of the european parliament and of the council, Official Journal of the European Union, L327, 1-72, 2000.

White, T. E.: Status of measurement techniques for coastal sediment transport, Coast. Engin., 35, 17-45, 1998.

Winter, C., Becker, M., Ernstsen, V. B., Hebbeln, D., Port, A., Bartholomä, A., Flemming, B., and Lunau, M.: In-situ observation of aggregate dynamics in a tidal channel using acoustics, laser diffraction and optics, J. Coast. Res., 50, 1173-1177, 2007.

Zielinski, O., Busch, J. A., Cembella, A. D., Daly, K. L., Engelbrektsson, J., Hannides, A. K., and Schmidt, H.: Detecting marine hazardous substances and organisms: sensors for pollutants, toxins, and pathogens, Ocean Sci., 5, 329-349, doi:10.5194/os5-329-2009, 2009. 